\title{
COMPONENTES NÃO CARCAÇA DE BOVINOS NELORE ABATIDOS COM DIFERENTES PESOS
}

\section{NON-CARCASS COMPONENTS OF NELLORE BOVINES SLAUGHTERED WITH DIFFERENT WEIGHTS}

\author{
Fabiano Nunes Vaz ${ }^{1^{*}}$ \\ João Restle ${ }^{2}$ \\ João Teodoro Pádua ${ }^{3}$ \\ Cristiane Amorim Fonseca ${ }^{4}$ \\ Leonir Luiz Pascoal ${ }^{5}$ \\ Marcelo Machado Severo 5 \\ 1 Universidade Federal de Santa Maria, Centro de Ciências Rurais, Departamento de Educação Agrícola e \\ Extensão Rural, Santa Maria, RS, Brasil \\ 2Universidade Federal do Tocantins, Programa de Pós-graduação em Ciência Animal, Araguaína, TO, \\ Brasil. \\ ${ }^{3}$ Universidade Federal de Goiás, Escola de Veterinária e Zootecnia, Departamento de Produção Animal \\ Goiânia, GO, Brasil. \\ ${ }^{4}$ Instituto Federal do Triângulo Mineiro, Uberlândia, MG, Brasil \\ ${ }^{5}$ Universidade Federal de Santa Maria, Centro de Ciências Rurais, Departamento Zootecnia, Santa Maria, \\ RS, Brasil \\ *Autor para correspondência - pecpampa@gmail.com
}

\section{Resumo}

O objetivo do experimento foi realizar a avaliação do rendimento de componentes não carcaça provenientes do abate de machos Nelore, não castrados, abatidos com diferentes pesos. Foram utilizados 40 animais com peso corporal médio de $350 \mathrm{~kg}$ no inicio do confinamento. Em delineamento inteiramente casualizado, os animais foram divididos em quatro grupos: animais 0 e 2 dentes, com peso de carcaça de até $238,0 \mathrm{~kg}$ (jovens e carcaças leves); animais 2 dentes com peso de carcaça variando de 238,1 a 258,0 kg (jovens e carcaças médias); animais 2 dentes com peso de carcaça superior a 258,0 kg (jovens e carcaças pesadas) e animais com 4 ou 6 dentes, independente do peso de carcaça (adultos). Os animais foram confinados por 84 dias com dieta calculada para atingir ganho de peso médio de 1,2 kg/dia. $O$ peso do couro foi maior nos animais jovens e pesados em relação aos jovens e leves e aos adultos. Foi verificada diferença no percentual de fígado, que foi maior nos animais jovens pesados $(1,91 \%)$ em relação aos jovens com carcaça média $(1,49 \%)$. A análise econômica mostrou que os animais jovens com carcaça pesada deixam a maior receita com componentes não carcaça ( $\mathrm{R} \$ 208,00)$, seguidos dos jovens médios ( $\mathrm{R} \$ 193,56)$, sendo a receita dos animais adultos e dos jovens e leves $\mathrm{R} \$ 21,42$ e $\mathrm{R} \$ 23,42$, respectivamente, inferior aos primeiros. Os componentes não carcaça agregam à indústria de $\mathrm{R} \$ 0,71$ a $\mathrm{R} \$ 0,80$ por quilograma de carcaça. Palavras-chave: Bos indicus; confinamento; couro; co-produtos; miúdos bovinos; rendimento industrial. 


\begin{abstract}
The objective of the experiment was to evaluate byproducts yield of non-castrated Nellore males slaughtered at different weights. Forty Nellore males with average weight of $350 \mathrm{~kg}$ at the beginning of the feedlot were used. In a completely randomized design, the animals were divided into four groups: 0 to 2-teeth animals with carcass weight up to $238.0 \mathrm{~kg}$ (young and light carcasses); 2-teeth animal with carcass weights ranging from 238.1 to $258.0 \mathrm{~kg}$ (young and middle weight carcasses); 2-teeth animal with carcass weight over $258.0 \mathrm{~kg}$ (young and heavy carcasses) and animals with four or six teeth, regardless of carcass weight (adults). Animals were fed during 84 days with diet calculated to reach average weight gain of $1.2 \mathrm{~kg} / \mathrm{day}$. Hide weight was higher for young and heavy animals in relation to young and light and adult animals. Regarding the noncarcass components yield, we verified difference for liver percentage, which was higher for young and heavy animals $(1.91 \%)$ in relation to young with middle weight carcasses $(1.49 \%)$. Economic analysis showed that the non-carcass components of young animals with heavy carcass result in higher income ( $\mathrm{R} \$ 208.00)$, followed by young animals with middle weight carcasses ( $\mathrm{R} \$ 193.56)$, and the incomes of adult and of young and light animals, respectively, $\mathrm{R} \$ 21.42$ and $\mathrm{R} \$ 23.42$ lower than the first one. No carcass components add to industry from $R \$ 0.71$ to $R \$ 0.80$ per carcass kilogram.
\end{abstract}

Keywords: beef cattle offal; Bos indicus; byproducts; feedlot; hide; industrial yield.

Recebido em: 28 maio 2012

Aceito em: 16 janeiro 2015

\title{
Introdução
}

A avaliação dos componentes não carcaça é importante para a indústria frigorífica, pois, a partir de seu bom aproveitamento, pode ser viabilizada uma melhor remuneração pelos animais. Os pesos absoluto e relativo ao peso do corpo vazio e dos componentes não carcaça são influenciados, entre outros fatores, pelo grupo genético, condição sexual e sistema de alimentação ${ }^{(1,2)}$. Salientando a necessidade de se valorizar os componentes não carcaça de cordeiros, Carvalho et al. ${ }^{(3)}$ citam que esses produtos podem chegar a $34,65 \%$ do peso vivo de um ovino, agregando valor para a remuneração das cadeias produtivas da carne ovina.

Os miúdos bovinos respondem por grande parte da exportação do complexo carne bovina, sendo importante fonte de proteína bruta para culturas orientais ou economias subnutridas de baixa renda. O objetivo deste trabalho foi avaliar o rendimento de subprodutos do abate de machos Nelore jovens não castrados, abatidos com diferentes pesos.

\section{Material e Métodos}

O trabalho de terminação dos animais em confinamento ocorreu de 26 de julho a 03 de novembro de 2003, desenvolvido na Fazenda Morada Nova, estado de Goiás, sendo o clima da região classificado como Tropical de Savana, com temperatura média anual de $21,9{ }^{\circ} \mathrm{C}$ e precipitação 
pluviométrica de $1.487 \mathrm{~mm}$. Foram utilizados 40 machos Nelore, não castrados, com peso corporal médio no inicio do confinamento de $350 \mathrm{~kg}$, recriados em Brachiaria brizantha cv. Marandu, suplementados com suplemento mineral comercial.

Foram testados quatro grupos: animais com 0 ou 2 dentes, com peso de carcaça de até $238,0 \mathrm{~kg}$ (jovens e carcaças leves); animais com 2 dentes, com peso de carcaça variando de 238,1 a 258,0 kg (jovens e carcaças médias); animais com 2 dentes, com peso de carcaça superior a 258,0 kg (jovens e carcaças pesadas) e animais com 4 ou 6 dentes, independente do peso de carcaça (adultos).

A dieta oferecida aos animais continha $60 \%$ de silagem de milho como volumoso e $40 \%$ de concentrado à base de milho, farelo de trigo, farelo de soja e minerais. A dieta possuía 11,9\% de proteína bruta e 68,3\% de NDT, calculada para atingir ganho de peso de 1,2 kg/dia.

O abate dos bovinos foi realizado num mesmo dia, em estabelecimento com Serviço de Inspeção Federal (SIF). Após o abate, foi conferida a dentição dos animais e feita a coleta e pesagem dos subprodutos após a evisceração e toalete das carcaças. À medida que os animais eram abatidos, foi realizada a esfola, sendo removidos e pesados todos os órgãos, tão logo ocorria a evisceração de cada animal. O couro em sangue correspondeu ao órgão desprovido de orelhas e vassoura da cauda. O rabo foi retirado da carcaça na linha de abate, após a remoção do couro da parte traseira da carcaça. A carne da cabeça foi retirada após a remoção da língua, separação do maxilar e da caixa craniana. Os principais músculos que compreendem a carne de cabeça são os masseteres e músculos da articulação junto ao pescoço e base da língua. A língua representa o órgão examinado pela inspeção sanitária e, em seguida, deu-se a remoção dos músculos conectivos, gorduras e osso hióide.

A ferida de sangria foi removida na linha de abate e, depois de retirados os tecidos com acúmulo de sangue, restaram os músculos que apresentavam coloração mais escura em função do processo de sangria e consequente rompimento dos vasos que irrigam a região. A carne industrial foi removida de junto aos tendões, junto ao reto e toaletes das vísceras.

O fígado foi obtido após a inspeção sanitária e a remoção da vesícula biliar. O diafragma foi removido logo após a evisceração do animal abatido, de ambos os lados da carcaça. O lombinho (músculo Longus colli) foi retirado da base das artérias torácicas, do lado interno da carcaça, no momento em que também foram removidos o nervo cervical e as entranhas (músculo diafragma). O pulmão e o coração foram obtidos depois da inspeção sanitária e separação da traqueia. $\mathrm{O}$ baço e pâncreas foram obtidos na mesa de vísceras, enquanto os rins foram retirados da carcaça e separados da gordura renal. As chamadas vísceras brancas correspondem aos tendões, o vergalho e os testículos, a medula cervical, a traqueia, a aorta e o nervo cervical. Os quatro primeiros foram removidos na linha de abate e apenas lavados. A aorta e a traqueia foram retiradas na mesa de vísceras e depois separadas das gorduras acumuladas na região. Os intestinos foram esvaziados e lavados e a mucosa extraída desse processo foi recolhida em bacias para pesagem.

O omaso, o rúmen e o retículo foram esvaziados, lavados, alvejados e pré-cozidos antes de serem comercializados. Como este se tratou de um trabalho de análise econômica, foram usados os pesos desses órgãos depois de processados. A gordura mesentérica e omental corresponderam à gordura do trato digestório, removido durante a evisceração.

Além das vísceras, as carcaças também foram pesadas logo após o abate e antes da lavagem, obtendo-se o peso de carcaça quente. Os componentes não carcaça foram pesados ainda quentes, depois de lavados e realizados os recortes de preparo para a comercialização. Os pesos obtidos foram ajustados para o peso de carcaça quente, obtendo-se a relação de rendimento percentual 
desses. A classificação e tipificação das carcaças ocorreram conforme a Portaria N. 612 do Ministério da Agricultura, Pecuária e Abastecimento.

O delineamento experimental foi inteiramente casualizado, conforme o modelo estatístico: $\mathrm{Y}_{\mathrm{ij}}=\mathrm{m}+\mathrm{g}_{\mathrm{i}}+\mathrm{e}_{\mathrm{ij}}$, sendo, $\mathrm{Y}_{\mathrm{ij}} \mathrm{o}$ valor observado no i-ésimo grupo de animais, na j-ésima repetição; $\mathrm{m}=\mathrm{a}$ média geral da variável; $\mathrm{g}_{\mathrm{i}} \mathrm{o}$ efeito do i-ésimo grupo de animais; e $\mathrm{e}_{\mathrm{ij}} \mathrm{o}$ efeito aleatório associado a cada observação.

Utilizou-se um programa estatístico para realizar as análises de variância pelo procedimento de Modelos Lineares Gerais, suas médias ajustadas pelo método dos Quadrados Mínimos e comparadas pelo Teste de Tukey ( $5 \%$ de probabilidade de erro). Nas análises de correlação, foi considerado o nível de probabilidade de erro de $1 \%$.

\section{Resultados e Discussão}

Os pesos dos produtos chamados de "vísceras vermelhas" (Tabela 1) apresentaram diferença $(\mathrm{P}<0,05)$ no peso dos pulmões, sendo verificado menor valor nos animais jovens e com carcaças leves $(1,77 \mathrm{~kg}$ ) em relação aos demais grupos (em média 2,02 kg), indicando uma relação dessa víscera com o peso corporal dos animais. Esse produto é usado na produção de proteína animal ou comercializado para produção de ração para cães e gatos.

No presente estudo, os pesos médios de fígado, baço e rins foram de 4,40; 0,96 e 0,66 kg, respectivamente, características que se mostraram semelhantes entre os grupos $(\mathrm{P}>0,05)$, possivelmente devido à similaridade no nível energético das dietas. Espera-se que animais alimentados com altas densidades energéticas possuam maior desenvolvimento dos órgãos mais ativados para responder a um metabolismo mais intenso, como é o caso dos órgãos citados ${ }^{(4)}$.

$\mathrm{O}$ peso de couro em sangue também foi influenciado pelos grupos de carcaças $(\mathrm{P}<0,05)$, sendo que os animais jovens e pesados apresentaram maior valor do que os jovens e leves e os adultos. Observando-se os valores percentuais (Tabela 2), constatou-se que não houve diferença estatística $(\mathrm{P}>0,05)$ entre os grupos de carcaça para o rendimento de couro dos animais. Animais em maturidade mais avançada podem apresentar menor variação no peso do couro, não diferindo em peso de animais mais jovens.

Entre as vísceras vermelhas (Tabela 2), observou-se que o fígado mostrou menor rendimento em relação ao peso de carcaça quente nos animais jovens médios $(1,49 \%)$ comparados aos jovens pesados $(1,91 \%)$. Com a correlação positiva e alta entre peso dos órgãos internos e o peso de corpo vazio e a massa muscular de bovinos, o fígado é o melhor indicador da massa corporal, por aumentar o desenvolvimento em resposta ao maior metabolismo de uma maior massa corporal. Em ovinos, Majdoub-Mathlouthi et al. ${ }^{(5)}$ observaram que dietas com maior nível de concentrado aumentam o percentual de fígado, pois forçam o maior desenvolvimento desse órgão em resposta a uma taxa metabólica mais elevada. Trabalhando com bovinos Nelore, Pazdiora et al. ${ }^{(6)}$, analisando as classes de pesos 350, 455, 485, 555 e $580 \mathrm{~kg}$, verificaram regressão negativa para percentual de fígado em relação ao peso de carcaça quente dos animais, à medida que o peso de abate aumentou. $\mathrm{O}$ rendimento de carne de cabeça, que é destinada para produção de embutidos e carne moída, atingiu $0,74 \%$ do peso de carcaça. 
Tabela 1: Pesos das vísceras vermelhas resultantes do abate de machos inteiros da raça Nelore terminados com diferentes pesos e dentições

\begin{tabular}{lccccccc}
\hline Variável & $\begin{array}{c}\text { Jovens } \\
\text { leves }\end{array}$ & $\begin{array}{c}\text { Jovens } \\
\text { médios }\end{array}$ & $\begin{array}{c}\text { Jovens } \\
\text { pesados }\end{array}$ & Adultos & $\mathbf{R}^{2}$ & $\mathbf{C V , \%}$ & P>F \\
\hline Número de animais & 12 & 9 & 10 & 9 & & & \\
Peso de carcaça quente, kg & 230 & 249 & 273 & 264 & & & \\
Rabo, kg & 1,11 & 1,06 & 1,31 & 1,05 & 0,20 & 19,6 & 0,14 \\
Carne de cabeça, kg & 1,73 & 1,90 & 1,86 & 1,88 & 0,09 & 12,7 & 0,34 \\
Carne industrial, kg & 1,31 & 1,51 & 1,51 & 1,65 & 0,12 & 23,2 & 0,18 \\
Carne da sangria, kg & 1,81 & 2,11 & 1,95 & 2,21 & 0,07 & 27,6 & 0,40 \\
Fígado, kg & 4,25 & 3,85 & 4,99 & 4,52 & 0,17 & 20,8 & 0,07 \\
Entranha, kg & 0,75 & 0,83 & 0,76 & 0,75 & 0,05 & 16,1 & 0,56 \\
Língua, kg & 0,97 & 1,07 & 1,02 & 1,02 & 0,15 & 8,7 & 0,12 \\
Lombinho, kg & 0,43 & 0,49 & 0,51 & 0,44 & 0,14 & 18,5 & 0,15 \\
Pulmão, kg & $1,77^{\mathrm{b}}$ & $2,01^{\mathrm{a}}$ & $2,03^{\mathrm{a}}$ & $2,03^{\mathrm{a}}$ & 0,24 & 11,4 & 0,02 \\
Coração, kg & 0,97 & 1,03 & 1,08 & 1,08 & 0,09 & 15,2 & 0,32 \\
Baço, kg & 0,90 & 0,87 & 1,06 & 0,99 & 0,15 & 18,6 & 0,12 \\
Pâncreas, kg & 0,16 & 0,13 & 0,15 & 0,15 & 0,26 & 16,6 & 0,78 \\
Rins, kg & 0,63 & 0,66 & 0,70 & 0,67 & 0,08 & 14,0 & 0,42 \\
Couro em sangue, kg & $45,6^{\mathrm{bc}}$ & $49,0^{\text {ab }}$ & $50,9^{\mathrm{a}}$ & $44,3^{\mathrm{c}}$ & 0,37 & 7,5 & 0,01 \\
a,b,c na linha, na comparação entre grupos de animais, representa que as médias diferem $(\mathrm{P}<0,05)$ pelo \\
Teste de Tukey.
\end{tabular}

Tabela 2: Rendimentos das vísceras vermelha sem relação ao peso de carcaça quente resultantes do abate de machos inteiros da raça Nelore terminados com diferentes pesos e dentições

\begin{tabular}{lccccccc}
\hline Variável & $\begin{array}{c}\text { Jovens } \\
\text { leves }\end{array}$ & $\begin{array}{c}\text { Jovens } \\
\text { médios }\end{array}$ & $\begin{array}{c}\text { Jovens } \\
\text { pesados }\end{array}$ & Adultos & $\mathbf{R}^{2}$ & $\begin{array}{c}\mathbf{C V}, \\
\text { \% }\end{array}$ & P>F \\
\hline Número de animais & 12 & 9 & 10 & 9 & & & \\
Dentição média & 1,33 & 2,00 & 2,00 & 4,44 & & & \\
Peso de carcaça quente, kg & 230 & 249 & 273 & 264 & & & \\
Rabo, \% & 0,47 & 0,41 & 0,50 & 0,42 & 0,16 & 18,6 & 0,10 \\
Carne de cabeça, \% & 0,74 & 0,75 & 0,71 & 0,76 & 0,05 & 11,4 & 0,61 \\
Carne industrial, \% & 0,56 & 0,60 & 0,58 & 0,68 & 0,08 & 24,5 & 0,37 \\
Carne da sangria, \% & 0,77 & 0,82 & 0,74 & 0,89 & 0,07 & 25,2 & 0,43 \\
Fígado, \% & $1,81^{\text {ab }}$ & 1,49 b & $1,91^{\text {a }}$ & $1,84^{\text {ab }}$ & 0,21 & 17,3 & 0,04 \\
Entranha, \% & 0,32 & 0,32 & 0,29 & 0,30 & 0,10 & 13,4 & 0,29 \\
Língua, \% & 0,41 & 0,42 & 0,39 & 0,42 & 0,09 & 7,9 & 0,30 \\
Lombinho, \% & 0,18 & 0,19 & 0,19 & 0,18 & 0,04 & 16,6 & 0,67 \\
Pulmão, \% & 0,76 & 0,79 & 0,78 & 0,83 & 0,09 & 10,8 & 0,34 \\
Coração, \% & 0,41 & 0,40 & 0,41 & 0,44 & 0,06 & 11,8 & 0,52 \\
Baço, \% & 0,07 & 0,06 & 0,06 & 0,07 & 0,13 & 19,5 & 0,19 \\
Pâncreas, \% & 0,07 & 0,05 & 0,05 & 0,06 & 0,63 & 15,3 & 0,32 \\
Rins, \% & 0,27 & 0,25 & 0,27 & 0,27 & 0,04 & 10,8 & 0,65 \\
Couro em sangue, \% & 19,57 & 19,46 & 19,54 & 18,06 & 0,13 & 8,53 & 0,15 \\
\hline a,b,c na linha, na comparação entre grupos de animais, representa que as médias diferem $(\mathrm{P}<0,05)$ pelo \\
Teste de Tukey.
\end{tabular}

Não houve diferença significativa $(\mathrm{P}>0,05)$ entre os grupos de carcaça estudados para os pesos de vísceras brancas (Tabela 3). Das vísceras brancas, o componente mais representativo para a 
indústria frigorífica é o rúmen, que, vazio, atingiu mais de $3 \mathrm{~kg}$ em todos os grupos, sendo importante para a geração de receitas e representou, em média, 30,4\% da receita obtida com vísceras brancas e 5,9\% da receita total obtida com produtos não carcaça.

Tabela 3: Pesos das vísceras brancas resultantes do abate de machos inteiros da raça Nelore terminados com diferentes pesos e dentições

\begin{tabular}{lccccccc}
\hline Variável & $\begin{array}{c}\text { Jovens } \\
\text { leves }\end{array}$ & $\begin{array}{c}\text { Jovens } \\
\text { médios }\end{array}$ & $\begin{array}{c}\text { Jovens } \\
\text { pesados }\end{array}$ & $\begin{array}{c}\text { Adultos } \\
\mathbf{R}^{\mathbf{2}}\end{array}$ & $\begin{array}{c}\mathbf{C V}, \\
\text { \% }\end{array}$ & P>F \\
\hline Número de animais & 12 & 9 & 10 & 9 & & & \\
Dentição média & 1,33 & 2,00 & 2,00 & 4,44 & & & \\
Peso de carcaça quente, kg & 230 & 249 & 273 & 264 & & & \\
Aorta, kg & 0,17 & 0,16 & 0,15 & 0,15 & 0,02 & 19,6 & 0,82 \\
Omaso, kg & 0,63 & 0,71 & 0,65 & 0,65 & 0,07 & 16,2 & 0,42 \\
Rúmen, kg & 3,07 & 3,18 & 3,71 & 3,35 & 0,10 & 23,6 & 0,28 \\
Retículo, kg & 0,41 & 0,40 & 0,42 & 0,39 & 0,05 & 12,1 & 0,54 \\
Tendões, kg & 0,73 & 0,67 & 0,85 & 0,75 & 0,12 & 22,9 & 0,18 \\
Vergalho, kg & 0,27 & 0,28 & 0,30 & 0,27 & 0,07 & 15,3 & 0,40 \\
Intestino grosso, kg & 0,50 & 0,47 & 0,45 & 0,43 & 0,04 & 26,4 & 0,63 \\
Intestino delgado, kg & 1,65 & 1,71 & 2,06 & 1,47 & 0,13 & 32,7 & 0,15 \\
Gordura mesentérica, kg & 0,20 & 0,23 & 0,24 & 0,23 & 0,14 & 17,5 & 0,14 \\
Mucosa, kg & 0,66 & 0,67 & 0,64 & 0,62 & 0,02 & 22,2 & 0,85 \\
Testículos, kg & 0,41 & 0,41 & 0,45 & 0,45 & 0,02 & 26,1 & 0,79 \\
Medula, kg & 0,12 & 0,14 & 0,13 & 0,12 & 0,04 & 23,0 & 0,68 \\
Nervo, kg & 0,29 & 0,33 & 0,31 & 0,32 & 0,02 & 28,0 & 0,81 \\
Traquéia, kg & 0,26 & 0,30 & 0,27 & 0,29 & 0,10 & 17,3 & 0,30 \\
\hline
\end{tabular}

Comparando animais em pastejo restrito ou ad libitum, Melo et $\mathrm{al}^{(7)}$ analisaram os percentuais dos órgãos do trato digestivo vazio e verificaram que os valores de rúmen vazio foram similares em percentagem do peso de abate, mas significativamente maiores nos animais alimentados sob restrição, mais leves ao abate, casos em que o órgão foi estimado em relação ao peso de corpo vazio. No presente trabalho, não houve diferenças $(\mathrm{P}>0,05)$ nos percentuais de vísceras brancas (Tabela 4) entre os grupos estudados, mostrando-se que o tamanho corporal é definitivo para o tamanho desses órgãos. Ao serem somados os percentuais de rúmen + retículo, observou-se para essa soma $1,91 \%$.

Valores inferiores dos órgãos internos podem ser reflexo do menor arqueamento de costelas dos animais zebuínos do presente trabalho em relação a bovinos de raças europeias, que comportam um trato digestivo representativamente mais desenvolvido ${ }^{(1-2)}$. Esse fato se acentuou à medida que os animais do presente estudo receberam $40 \%$ da dieta na forma de concentrado. O crescimento dos estômagos responde ao tipo de dieta, aos suplementos usados e ao teor de fibra da dieta ingerida ${ }^{(8-9)}$. Efeito do teor de fibra no desenvolvimento do trato digestivo foi verificado em ovinos por Tonetto et al. ${ }^{(10)}$, que compararam o percentual de rúmen + retículo vazios em relação ao peso vivo, observando valores de 0,$50 ; 0,56$ e $0,60 \%$, respectivamente, para cordeiros terminados em pastagem com baixo teor de fibra, suplementados em pastagem e confinados. Terry et al. ${ }^{(11)}$ verificaram percentual de intestino delgado em relação ao peso vivo de $2,22 \%$ e $1,98 \%$, respectivamente, para fêmeas e machos mestiços europeu x zebuíno com menos de $50 \%$ Bos indicus. Já o percentual de 
intestino grosso foi de $3,93 \%$ e $3,49 \%$, citados na mesma ordem.

Tabela 4: Percentagens das vísceras brancas em relação ao peso de carcaça quente resultantes do abate de machos inteiros da raça Nelore terminados com diferentes pesos e dentições

\begin{tabular}{|c|c|c|c|c|c|c|c|}
\hline Variável & $\begin{array}{c}\text { Jovens } \\
\text { leves }\end{array}$ & $\begin{array}{l}\text { Jovens } \\
\text { médios }\end{array}$ & $\begin{array}{c}\text { Jovens } \\
\text { pesados }\end{array}$ & Adultos & $\mathbf{R}^{2}$ & $\begin{array}{c}\mathrm{CV}, \\
\%\end{array}$ & $\mathbf{P}>\mathbf{F}$ \\
\hline Número de animais & 12 & 9 & 10 & 9 & & & \\
\hline Dentição média & 1,33 & 2,00 & 2,00 & 4,44 & & & \\
\hline Peso de carcaça quente, $\mathrm{kg}$ & 230 & 249 & 273 & 264 & & & \\
\hline Aorta, $\%$ & 0,39 & 0,34 & 0,40 & 0,41 & 0,12 & 18,5 & 0,22 \\
\hline Omaso, \% & 0,27 & 0,28 & 0,25 & 0,26 & 0,06 & 17,7 & 0,50 \\
\hline Rúmen, \% & 1,31 & 1,24 & 1,42 & 1,36 & 0,04 & 23,4 & 0,66 \\
\hline Retículo, \% & 0,17 & 0,16 & 0,16 & 0,15 & 0,13 & 12,8 & 0,15 \\
\hline Tendões, \% & 0,31 & 0,26 & 0,32 & 0,31 & 0,11 & 21,8 & 0,23 \\
\hline Vergalho, \% & 0,11 & 0,11 & 0,11 & 0,11 & 0,02 & 13,5 & 0,85 \\
\hline Intestino grosso, $\%$ & 0,21 & 0,18 & 0,17 & 0,18 & 0,11 & 27,1 & 0,21 \\
\hline Intestino delgado, $\%$ & 0,71 & 0,68 & 0,78 & 0,60 & 0,08 & 33,4 & 0,39 \\
\hline Gordura mesentérica, \% & 0,08 & 0,09 & 0,09 & 0,09 & 0,02 & 17,6 & 0,86 \\
\hline Mucosa, $\%$ & 0,28 & 0,26 & 0,24 & 0,25 & 0,06 & 24,4 & 0,46 \\
\hline Testículos, \% & 0,17 & 0,16 & 0,17 & 0,18 & 0,02 & 26,4 & 0,79 \\
\hline Medula, \% & 0,05 & 0,05 & 0,05 & 0,05 & 0,02 & 25,0 & 0,80 \\
\hline Nervo, $\%$ & 0,12 & 0,13 & 0,12 & 0,13 & 0,01 & 27,7 & 0,91 \\
\hline Traquéia, \% & 0,11 & 0,11 & 0,10 & 0,11 & 0,06 & 15,9 & 0,55 \\
\hline
\end{tabular}

Referindo-se ao sistema de terminação de cordeiros, Carvalho et al. ${ }^{(3)}$ relataram diferença nos percentuais de gorduras interna e renal a favor de animais confinados em relação aos animais terminados em pastejo sem suplemento, sendo que os últimos mostraram maior percentagem de vísceras verdes cheias $(32,4$ contra $27,7 \%)$ e vísceras verdes vazias $(9,4$ contra $8,0 \%)$ em relação aos cordeiros confinados.

A análise das receitas obtidas com os componentes não carcaça (Tabela 5) mostra que o couro em sangue, seguido pelo fígado, são os itens mais importantes da receita industrial, responsáveis por $58 \%$ do valor obtido com os componentes não carcaça. Se forem adicionados a estes a soma das carnes de cabeça, da sangria e carne industrial, esses valores passam a representar mais de 2/3 da receita industrial de componentes não carcaça. Comparando genótipos Nelore e Charolês, Catellam et al. ${ }^{(1)}$ afirmam que zebuínos apresentaram valores similares aos europeus para rendimento dos órgãos internos, mas foram superiores na proporção de órgãos externos, notadamente o couro, importante fonte de receita para a indústria frigorífica.

É recorrente o pedido dos produtores rurais por remuneração pelo couro e pelas vísceras, o que seria bastante justo para aqueles produtores que investem em sanidade e cuidam da qualidade do couro dos animais destinados ao abate. No entanto, essa remuneração seria mais um item de discussão na relação comercial entre empresa frigorífica e produtores rurais, pois, além do conflito que ainda existe em relação ao rendimento de carcaça, existiria também discussão a respeito da condenação dos componentes não carcaça e qualidade do couro. Para completar, quando um frigorífico oferece um determinado valor por arroba de carcaça, deixa claro que está esperando, além da carcaça, todos 
componentes não carcaça que conseguirá aproveitar e, com a receita de todos os produtos, remunerar o produtor.

Dessa forma, pode-se inferir que o peso de carcaça é apenas um indexador pela compra de uma série de produtos, sendo que alguns serão aproveitados para a geração de receitas, como a carcaça, o couro e as vísceras, os quais estão relacionados ao peso corporal dos animais. Se todos frigoríficos fossem obrigados a pagar pelos componentes não carcaça, obviamente ofereceriam um valor menor pela arroba de carcaça, em um simples ajuste de mercado. Em uma comparação cotidiana, pode-se dizer que o consumidor que compra e leva para casa uma bandeja de bifes de alcatra, compra também o direito de reutilizar a bandeja ao invés de descartá-la, pois o valor dessa embalagem está embutido no preço que ele pagou pela alcatra.

Tabela 5: Receitas industriais ${ }^{*}$ (em R\$) com os componentes não carcaça do abate de machos inteiros da raça Nelore terminados com diferentes pesos e dentições

\begin{tabular}{|c|c|c|c|c|c|}
\hline Variável & $\mathbf{R S / \mathbf { k g }}$ & $\begin{array}{c}\text { Jovens } \\
\text { leves }\end{array}$ & $\begin{array}{l}\text { Jovens } \\
\text { médios }\end{array}$ & $\begin{array}{c}\text { Jovens } \\
\text { pesados }\end{array}$ & Adultos \\
\hline & \multicolumn{5}{|c|}{ Vísceras vermelhas } \\
\hline Couro em sangue & 1,95 & 88,92 & 95,55 & 99,26 & 86,38 \\
\hline Fígado & 4,50 & 19,13 & 17,33 & 22,46 & 20,34 \\
\hline Carnes (cabeça+industrial+sangria) & 3,55 & 17,22 & 19,60 & 18,89 & 20,38 \\
\hline Rabo & 8,00 & 8,88 & 8,48 & 10,48 & 8,40 \\
\hline Língua & 4,10 & 3,98 & 4,39 & 4,18 & 4,18 \\
\hline Entranha & 3,55 & 2,66 & 2,95 & 2,70 & 2,66 \\
\hline Coração & 2,50 & 2,43 & 2,58 & 2,70 & 2,70 \\
\hline Lombinho & 5,55 & 2,39 & 2,72 & 2,83 & 2,44 \\
\hline Pulmão & 0,90 & 1,59 & 1,81 & 1,83 & 1,83 \\
\hline Rins & 1,25 & 0,79 & 0,83 & 0,88 & 0,84 \\
\hline Baço + pâncreas & 0,70 & 0,74 & 0,70 & 0,85 & 0,80 \\
\hline \multirow[t]{2}{*}{ Subtotal 1, RS } & & 148,73 & 156,94 & 167,06 & 150,95 \\
\hline & \multicolumn{5}{|c|}{ Vísceras brancas } \\
\hline Intestinos grosso + delgado & 5,20 & 11,18 & 11,33 & 13,05 & 9,88 \\
\hline Rúmen & 3,40 & 10,44 & 10,81 & 12,61 & 11,39 \\
\hline Tendões & 5,10 & 3,72 & 3,42 & 4,34 & 3,83 \\
\hline Omaso & 3,80 & 2,39 & 2,70 & 2,47 & 2,47 \\
\hline Vergalho & 7,75 & 2,09 & 2,17 & 2,33 & 2,09 \\
\hline Retículo & 4,50 & 1,85 & 1,80 & 1,89 & 1,76 \\
\hline Gord. mesentérica + mucosa & 2,05 & 1,76 & 1,84 & 1,80 & 1,74 \\
\hline Aorta & 4,60 & 0,78 & 0,74 & 0,69 & 0,69 \\
\hline Nervo & 1,65 & 0,48 & 0,54 & 0,51 & 0,53 \\
\hline Testículos & 1,15 & 0,47 & 0,47 & 0,52 & 0,52 \\
\hline Medula & 3,15 & 0,38 & 0,44 & 0,41 & 0,38 \\
\hline Traquéia & 1,20 & 0,31 & 0,36 & 0,32 & 0,35 \\
\hline Subtotal 2, RS & & 35,85 & 36,62 & 40,94 & 35,63 \\
\hline
\end{tabular}

Os dados mostram que a relação entre as receitas com vísceras vermelhas e com vísceras brancas foi 4,18 (Tabela 6), indicando uma maior receita com os componentes chamados "vermelhos" e, 
dessa forma, a importância industrial dos mesmos, que representam, em média, $\mathrm{R} \$ 193,18$ de receita ao frigorífico.

Tabela 6: Relações econômicas entre as receitas industriais com os componentes não carcaça do abate de machos linteiros da raça Nelore terminados com diferentes pesos e dentições

\begin{tabular}{lrrrr}
\hline Variável & $\begin{array}{c}\text { Jovens } \\
\text { leves }\end{array}$ & $\begin{array}{c}\text { Jovens } \\
\text { médios }\end{array}$ & $\begin{array}{c}\text { Jovens } \\
\text { pesados }\end{array}$ & Adultos \\
\hline Relação subtotal 1 : subtotal 2 & 4,15 & 4,29 & 4,08 & 4,24 \\
Receita total (1+2), R \$ & 184,58 & 193,56 & 208,00 & 186,58 \\
Agregado por kg de carcaça, $\mathrm{R} \$ 1$ & 0,80 & 0,78 & 0,76 & 0,71 \\
\hline
\end{tabular}

${ }^{1}$ Receita total dividida pelo peso de carcaça.

A comparação entre os grupos de carcaça mostra receita similar entre animais com 4 ou 6 dentes e os animais jovens (2 dentes) e médios (Tabela 6). A diferença de receita entre os jovens e pesados $(\mathrm{R} \$ 208,00)$ e os jovens leves $(\mathrm{R} \$ 184,58)$ atinge $\mathrm{R} \$ 23,42$ e entre os primeiros e os adultos, $\mathrm{R} \$$ 21,42. Esses resultados mostram que, para o frigorífico, nem sempre o animal mais pesado é o mais interessante, pois os animais adultos, com peso de carcaça de $246 \mathrm{~kg}$ (Tabela 1), tiveram receita de componentes não carcaça ( $\mathrm{R} \$ 186,58)$ similar a animais de $230 \mathrm{~kg}$ (jovens e leves). Nos jovens, o incremento da receita foi praticamente linear com o peso de carcaça, gerando agregação de valor que variou de $R \$ 0,76$ a $R \$ 0,80$, contra $R \$ 0,71$ nos adultos.

$\mathrm{Na}$ análise das correlações (Tabela 7), observou-se uma grande maioria de correlações positivas $(\mathrm{P}<0,01)$ que indicam uma relação com o peso dos animais, por exemplo, a correlação $r=0,56$ entre carne de cabeça e língua, e $r=0,50$ entre a primeira e a ferida de sangria. Maior número de correlações de uma variável foi do coração, correlacionada positivamente com o baço, fígado, entranhas, lombinho, pulmão, rins, sangria e tendões.

Tabela 7: Correlações altamente significativas $(\mathrm{P}<0,01)$ das variáveis medidas por pesagem de machos inteiros da raça Nelore abatidos com diferentes pesos e dentições

\begin{tabular}{|c|c|c|c|c|c|c|c|c|c|c|c|c|c|c|}
\hline & $1^{*}$ & 2 & 3 & 4 & 5 & 6 & 7 & 8 & 9 & 10 & 11 & 12 & 13 & 14 \\
\hline Coração & & 0,66 & 0,43 & & 0,43 & 0,52 & 0,46 & 0,44 & 0,60 & & & & & \\
\hline Fígado & & & & & & & 0,54 & & 0,55 & & & & & \\
\hline Entranhas & & & & & 0,52 & & & & & & 0,41 & & & \\
\hline Língua & & & & & & & 0,42 & & & 0,49 & & & 0,41 & \\
\hline Lombinho & & & & & & 0,52 & & 0,49 & 0,43 & & 0,42 & & & \\
\hline Pulmão & & & & & & & & & & & 0,4 & & & \\
\hline Rins & & & & & & & & & & & & & 0,40 & \\
\hline Sangria & & & & & & & & & & 0,48 & & $-0,43$ & & \\
\hline Vergalho & & & & & & & & & & & & 0,39 & & \\
\hline $13^{*}$ & & & & & & & & & & & & & & 0,42 \\
\hline 15 & & & & 0,56 & & & & 0,50 & & 0,54 & & $-0,40$ & & \\
\hline 16 & & & & & & & & & & & & & & 0,43 \\
\hline Rabo & & 0,47 & & & & & & & 0,60 & & & & & \\
\hline Couro & & & & & & & & & & & & 0,44 & 0,41 & \\
\hline Rúmen & & & & & 0,59 & & 0,45 & & 0,61 & & & & & \\
\hline Retículo & & & & 0,41 & & & & & & 0,42 & & & & 0,43 \\
\hline Omaso & & & & & & & & 0,42 & & & & $-0,52$ & & \\
\hline Baço & 0,56 & 0,48 & & & & 0,49 & & & 0,40 & & & & & \\
\hline
\end{tabular}




\section{Conclusões}

Animais adultos possuem menor receita total de componentes não carcaça do que animais com dois dentes e com mais de $258 \mathrm{~kg}$ de carcaça, sendo que $58 \%$ desta receita é obtida com couro em sangue e fígado.

Não há diferença nos pesos e percentagens de rendimento de estômagos, como rúmen, omaso e retículo e nas carnes extraídas de partes não integrantes da carcaça, como carne de cabeça, carne da sangria e carne industrial.

\section{Referências}

1 Cattelam J, Freitas LS, Brondani IL, Silva JHS, Arboitte MZ, Weise MS. Características dos componentes externos e das gorduras descartadas de novilhos superprecoces não-castrados ou castrados de dois genótipos terminados em confinamento. Rev. Bras. Zootec. [periódico na Internet]. 2011 Aug [citado 2014 Aug 20] 40(8):1774-1780. Portuguese. Disponível em: 〈http://dx.doi.org/10.1590/S1516-35982011000800022〉. Acesso em outubro de 2014.

2 Peripolli V, Barcellos JOJ, Olmedo DAO, Lampert VN, Velho MMS. Componentes não-integrantes da carcaça de bovinos de três grupos genéticos terminados em confinamento ou pastejo rotacionado com suplementação. Rev. Bras. Saúde Prod. Anim. [periódico na Internet] 2013 Jan/Mar [citado 2014 Aug 11] 14(1):209-223.

Portuguese.

Disponível

em <http://revistas.ufba.br/index.php/rbspa/article/view/2664/1387> . Acesso em outubro de 2014.

3 Carvalho S, Brochier MA, Pivato J, Teixeira RC, Kieling R. Ganho de peso, características da carcaça e componentes não-carcaça de cordeiros da raça Texel terminados em diferentes sistemas alimentares. C Rural. [periódico na Internet]. 2007 Mar [citado 2014 Jul 17] 37(3):821-7. Portuguese. Disponível em: <http://dx.doi.org/10.1590/S0103-84782007000500030 >. Acesso em outubro de 2014.

4 Almeida Júnior GA, Costa C, Carvalho SMR, Panichi A, Persichetti Júnior P. Características de carcaças e dos componentes não-carcaça de bezerros holandeses alimentados após o desaleitamento com silagem de grãos úmidos ou grãos secos de milho ou sorgo. Rev Bras Zoot. [periódico na Internet]. 2008 Jan [citado 2014 Jun 22] 37(1):157-63. Portuguese. Disponível em: 〈http://dx.doi.org/10.1590/S151635982008000100023>. Acesso em outubro de 2014.

5 Majdoub-Mathlouthi L, Saïd B, Say A, Kraiem K. Effect of concentrate level and slaughter body weight on growth performances, carcass traits and meat quality of Barbarine lambs fed oat hay based diet. Meat Sci. [periódico na Internet]. 2013 Mar [citado 2014 Sep 29] 93(3):557-63. Disponível em <http://www.sciencedirect.com/science? ob=ArticleListURL\& method=list\& ArticleListID=718287732\&_sort=r\&_st=13view=c\&md5=ea3b690fe05d394dc031652e8b77e57a\&searchtype=a. $>$. Acesso em outubro de 2014.

6 Pazdiora RD, Resende FD, Faria MH, Siqueira GR, Almeida GBS, Sampaio RL et al. Animal performance and carcass characteristics of Nellore young bulls fed coated or uncoated urea slaughtered at different weights. Rev. Bras. Zootec. [periódico na Internet]. 2013 Apr [citado 2014 Aug 22] 42(4):.273-83. Disponível em: $\langle$ http://dx.doi.org/10.1590/S1516-35982013000400007>. Acesso em outubro de 2014.

7 Melo WS, Véras ASC, Fereira MA, Dutra Junior WM, Andrade DKB, Santos GRA. Cortes nobres, componentes do peso vivo e órgãos viscerais de bovinos mestiços de origem leiteira em condições de 
pastejo, restrito ou "ad libitum". Rev. Bras. Ci. Agr. [periódico na Internet]. 2007 Jan-Mar [citado 2014 Aug 21] 2(1):90-7. Portuguese. Disponível em: <http://agraria.pro.br/sistema/index.php?journal=agraria\&page=article\&op=view \&path\% 5B \% 5D =9 6\&path\%5B\%5D=75 >. Acesso em outubro de 2014.

8 Sainz RD, Bentley BE. Visceral organ mass and cellularity in growth-restricted and refed beef steers. J Anim Sci. 1997, 75(5):1229-36.

9 Macitelli F, Berchielli TT, Silveira RN, Andrade P, Lopes AD, Sato KJ et al. Biometria da carcaça e peso de vísceras e de órgãos internos de bovinos mestiços alimentados com diferentes volumosos e fontes proteicas. Rev Bras Zoot. [periódico na Internet]. 2005 May [citado 2014 Aug 11] 34(5):1751-62. Portuguese. Disponível em 〈http://dx.doi.org/10.1590/S1516-35982005000500037>. Acesso em outubro de 2014.

10 Tonetto CJ, Pires CC, Müller L, Rocha MG, Silva JHS, Frescura RBM et al. Rendimentos de cortes da carcaça, características da carne e componentes do peso vivo em cordeiros terminados em três sistemas de alimentação. Rev Bras Zoot. [periódico na Internet]. 2004 Jan [citado 2014 Aug 18] 33(1):234-41. Portuguese. Disponível em< http://dx.doi.org/10.1590/S1516-35982004000100027>. Acesso em outubro de 2014.

11 Terry CA, Knapp RH, Edwards JW, Mies WL, Savell JW, Cross HR. Yields of by-products from different cattle types. J Anim Sci. 1990, 68(12):4200-5. 